\title{
College Students' Perceptions of Personal Learning Environments Through the Lens of Digital Tools, Processes and Spaces
}

\author{
Nada Dabbagh ${ }^{1 \star}$, Helen Fake ${ }^{2}$ \\ ${ }^{1}$ Division of Learning Technologies, George Mason University, USA \{ndabbagh@gmu.edu\} \\ ²Division of Learning Technologies, George Mason University, USA \{hfake@gmu.edu\} \\ Received on 9 October 2016; revised on 12 October 2016; accepted on 14 October 2016; published on 15 January 2017 \\ DOI: 10.7821/naer.2017.1.215 \\ (ब) DE-NC-ND
}

\begin{abstract}
A review of the literature reveals there is a gap in the research regarding how students currently perceive PLEs and how they structure their PLEs to support their learning goals. The purpose of this study was to establish an understanding of college students' perceptions of PLEs and what digital tools are currently being used to structure PLEs in order to facilitate personal growth and development. Participants $(\mathrm{N}=109)$ were asked to share their perceptions of PLEs and what digital tools, devices, and services they use to create PLEs. Analysis of blog submissions revealed similarities and differences between the ways that undergraduate and graduate students perceive PLEs and how they characterize these learning spaces. Students reported using a variety of digital tools for learning however their expectations of digital tools were to foster discussion, collaboration, and interaction, organization, planning, and resource management, experiential learning, personalization and a desire for effective technology. The findings of this study have important implications with respect to the competencies and skills needed to create effective PLEs and the affordances of digital technologies needed to support PLE development.
\end{abstract}

KEYWORDS: PERSONAL LEARNING ENVIRONMENTS (PLES), INFORMAL LEARNING, INFORMATION TECHNOLOGY, ONLINE SYSTEMS, SELF-REGULATED LEARNING

\section{INTRODUCTION}

Personal Learning Environments or PLEs are a $21^{\text {st }}$ Century concept premised on Web 2.0 technologies and steadily gaining ground as an effective individual platform for student learning. PLEs enable the development of personal and social learning spaces and experiences empowering students to direct their own learning and develop self-regulated learning skills. They do so because they are built bottom-up by the student, starting with personal goals, information management and individual knowledge construction, and progressing to socially mediated knowledge and networked learning. PLEs have been described as self-initiated and interest-driven learning environments

*To whom correspondence should be addressed:
(Barron, 2006); unique creations of individual learners that help shape their explorations and realizations (Haskins, 2007); systems that help learners take control of and manage their own learning (Van Harmelen, 2008); methods and tools students use to organize and self-manage their learning (Adell \& Castañeda, 2010; Downes, 2007; Wilson, 2008); a freely assembled ecosystem consisting of any set of communication channels, cloud resources, Web apps and social media members (Gillet, 2013); and a potentially promising pedagogical approach for integrating formal and informal learning and fostering selfregulated learning (Dabbagh \& Kitsantas, 2012). Additionally, The New Media Consortium's 2012 K-12 Horizon Report describes PLEs as a process or pedagogical approach that is individualized by design, centered around each user's goals, and customized using a personalized collection of distributed and portable tools and resources to support formal and informal learning as well as one's ongoing social and professional activities.

Although not wedded to a particular technology, PLEs are primarily facilitated by cloud-based Web 2.0 technologies and services designed to help students create, organize, and share content, participate in collective knowledge generation, and manage their own meaning making (Dabbagh \& Reo, 2011b; Martindale \& Dowdy, 2010). A PLE can be regarded as a process that helps students organize the influx of information and resources that they are faced with on a daily basis into a personalized digital learning space or experience (Ash, 2013). Specifically, social media technologies are empowering students to take charge of their own learning, prompting them to create, organize and package learning content around their goals and learning approaches resulting in the development of PLEs that are increasingly self-directed and personalized (Johnson, Adams, \& Haywood, 2011; McLoughlin \& Lee, 2010; Rubin, 2010). Research on PLEs has shown that social media can facilitate the creation of PLEs that help learners aggregate and share the results of learning achievements, participate in collective knowledge generation, and manage their own meaning making (Dabbagh \& Kitsantas, 2012). However, despite these powerful learning affordances, students need support, guidance and pedagogical interventions to help them make the best possible use of social media to support their learning goals and achieve academic success (Cigognini, Pettenati, \& Edirisingha, 2011; Clark, Logan, Luckin, Mee \& Oliver, 2008). 
As an example, Valjataga, Pata, and Tammets (2011) examined students' perceptions of developing PLEs to support their learning in an educational technology course and found that students need guidance in developing skills and confidence in the selection, application, and use of social media tools for personalized learning and that new pedagogical models are needed to help students advance their self-direction and selfawareness in a PLE. Dabbagh and Kitsantas (2013) examined adult professionals' general use of social media and more specifically, how adult professionals use social media to create PLEs to achieve their learning goals. The findings showed that participants $(\mathrm{N}=87)$ tended to use blogs, wikis, and social media sharing technologies primarily for personal learning $(70 \%, 60 \%$, $62 \%$ respectively); social networking sites primarily for socializing and networking (72\%,60\%); and games and social media sharing technologies primarily for entertainment (88\%, 76\%). With respect to PLE development, blogs, microblogs, and social bookmarking tools were perceived as more useful for personal information management, whereas wikis, cloud-based technologies, social networks, and social media sharing tools were perceived as more useful for social interaction and collaboration. In a follow up study (Dabbagh, Kitsantas, AlFreith, \& Fake, 2015), participants reported being intrinsically motivated in using social media to create their PLE. Social media's ability to motivate people to learn through community engagement and inter-group communications has been well documented (Mason \& Rennie, 2007; McLoughlin \& Lee, 2010; Minocha \& Kerawalla, 2011).

Research also suggests that social media is enabling both formal and informal learning experiences in higher education. For example, Ebner, Lienhardt, Rohs and Meyer (2010) found that college students used microblogging for private informal communication and that this was an important factor in encouraging students to adopt more formal uses of microblogging. Conversely, Harrison (2011) found that college students perceived the use of blogs as a means to extend communication beyond the weekly class meetings promoting the development of informal learning communities. Additionally, the research suggests that social media are being increasingly used as tools for developing formal and informal learning spaces or experiences that start out as an individual learning platform or PLE, enabling individual knowledge management and construction, and evolve into a social learning platform or system where knowledge is socially mediated (Dabbagh \& Reo, 2011a; Kitsantas \& Dabbagh, 2010; Minocha \& Kerawalla, 2011).

It is clear from this research overview that PLEs are increasingly being discussed in the learning technologies literature and described as new generation learning environments that embody Web 2.0 characteristics of openness, personalization, collaboration, social networking, social presence, and user-generated content. Additionally, PLEs are becoming increasingly effective in addressing issues of learner control and personalization that are often absent in the institutional Learning Management System (LMS). While most higher education institutions are still primarily relying on the LMS to deliver instruction and facilitate learning, the discussion has evolved to the integration of social media in an LMS or more importantly, on how existing social media platforms can be used by the institution to support students' creation of PLEs (Chatti, 2010; Tu et al., 2012; Valjataga et al., 2011). However, not enough is known about college students' perceptions of
PLEs and what digital tools they are using to support learning. As Castañeda and Soto (2010) posited, students when arriving at university, have little experience or knowledge in the use of digital tools for learning or awareness of how Web 2.0 tools can be used for learning. The purpose of this study was to establish an understanding of college students' perceptions of PLEs, what digital tools they use to create and structure PLEs, and how they use those tools to facilitate personal growth and development.

\section{METHOD}

\subsection{Participants}

Participants (N=109) included students from a Mid-Atlantic University's graduate instructional design program $(n=34)$ as well as undergraduate and graduate students from a small liberal arts college in New England $(n=75)$. Of the students who participated in the study, 109 published a blog post to the project PLE website. All participants were required to be 18 years or older and enrolled in a degree program at the respective universities.

\subsection{Materials}

A blogpost was used to collect the data for this study. The goal of the blogpost was to document what digital devices and technologies students use to learn and what digital technologies students wished they had access to for learning in order to understand what PLEs look like and help students manage their digital learning spaces and experiences. The blogpost consisted of responses to the following 5 questions: (Q1) Who are you and what do you like to learn about? (academically, professionally, and/or personally), (Q2) What hardware do you use to learn? (e.g. smart phone, tablet, laptop, desktop), (Q3) What software do you use to learn? (e.g. search engines, mobile apps, social networks, eBooks, digital libraries, wikis, blogs, videos, podcasts), (Q4) What digital tools do you wish you had access to for learning? (e.g. any graphic organizers, mind-mapping tools, resource management tools, progress tracking tools, design tools, etc.), and (Q5) What might your ideal Personal Learning Environment (PLE) look like? Participants were also asked to provide their name or nickname and upload an optional photo of themselves for the post.

The blogposts were hosted on a Wordpress.org website (projectple.com) domain and server space from Reclaim Hosting and the Gravity Forms plug-in. The Gravity Forms plug-in allowed participants to submit their response directly to the projectPLE site. It is important to note that Wordpress.org was used as the project platform since site customizations (to include adding plug-ins) are not allowed on the Wordpress.com platform. Wordpress.org allowed us to populate student blog responses immediately as well as post on the user's behalf.

A graduate assistant moderated the submitted projectPLE posts in order to assure that all submissions were completed and formatted correctly. No changes were made to the content of the posts except to rotate images and eliminate duplicate submissions.

\subsection{Procedure}

Participation in the projectPLE blog was solicited differently at the respective institutions. At the small liberal arts college, undergraduate and graduate student responses were solicited through a student listserv. To incentivize students, contributing bloggers were offered an entry into a raffle for a $\$ 50$ gift card. 
Participants were made aware that their blog entry would be available for public consumption and that their responses would be viewable to people who were interested in student perceptions of PLEs. Flyers and professor classroom visits were also used as additional communications mechanisms to encourage participation in the study.

At the Mid-Atlantic University, participation was solicited during classroom sessions and through the departmental listserv. Students were offered two extra credit points towards their final course grade for completing a blog post. Announcements took place during the first week of classes of the spring semester. A script of what was included in the respective solicitation for participation is available in the appendix of this paper.

Once the students visited the projectPLE.com site to submit their blogpost, they were instructed to "Tell Your Story". This page included a five-question blog form, which would submit a post to the front page of the projectPLE site. Following submission, blog posts were reviewed by a moderator and published for public consumption. All blog entries are available for review at projectPLE.com. Figure 1 shows the projectPLE submission page.

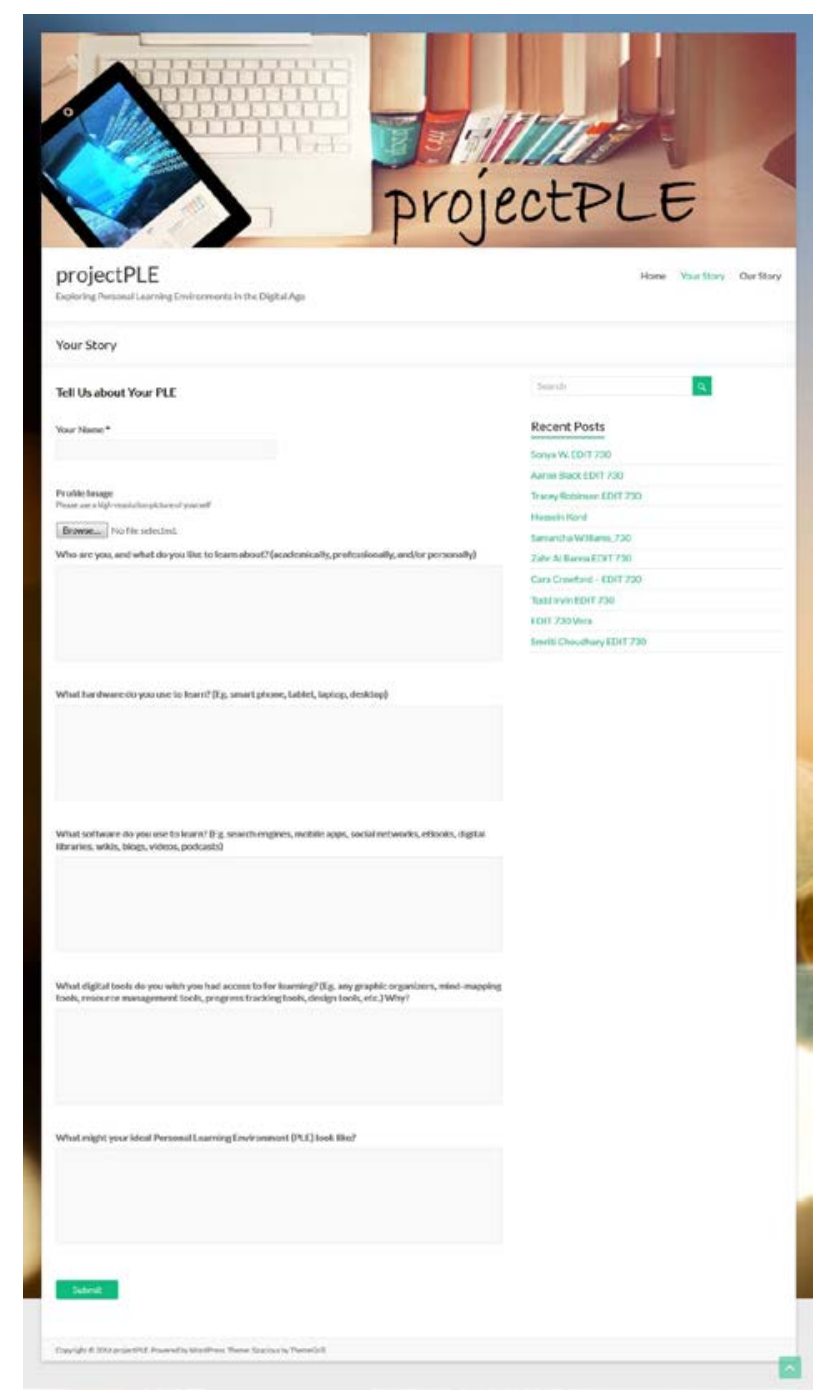

Figure 1. projectPLE Blog Submission Page

\subsection{Data Analysis}

Both qualitative and quantitative methods were employed to conduct a content analysis of the data associated with this study. As Greene (2007) notes, a mixed methods study affords multiple vantage points by which to view the data since it, “...is not intended to be a contest or competition, but more of a conversation..." (p. 27). Using mixed methods, student submitted blogposts were inductively analyzed for emergent themes (Q1 and Q5) and frequency counts were used to tally the number of times different hardware and software tools were mentioned (Q2, Q3, and Q4). More specifically, a conventional approach to content analysis was employed for the qualitative data (Hseih \& Shannon, 2005). The conventional approach of content analysis is common to studies researching a phenomenon such as the development of PLEs and is supportive of theoretical development. Blog data was pulled from the projectPLE.com website using the Wordpress CSV plug-in and aggregated into an Excel spreadsheet. This file was then shared on a secured Dropbox site to allow each researcher simultaneous access to the data. Student submitted blogposts were inductively analyzed for emergent qualitative themes (Q1 and Q5) and were individually coded using a line-by-line coding approach. Next, these codes were clustered into salient chunks of data, and reconciled between researchers to support inter-rater reliability (Maxwell, 2013). Independent analysis followed by code reconciliation supported inter-rater reliability. The quantitative data was collected by conducting a frequency count of the number of similar responses for each question. For example, in response to Q2, 72 of the small liberal arts college students mentioned using their laptop as a device for learning. A breakdown of the findings is presented next.

\section{RESULTS}

\subsection{Q1: Who are you, and what do you like to learn about?}

Students at the small liberal arts college reported a high interest in social issues [to include social work] $(n=16)$, children \& child development $(n=19)$, as well as other liberal arts topics. The question asked was general so not all participants reported interests and some reported more than one. Forty-two participants $(n=42)$ identified with their student status and twenty $(n=20)$ specifically mentioned their area of study. Other students identified themselves based on their place of origin, favorite hobbies, attributes, connections to family, jobs or career aspirations. Below are responses that are characteristic of the participants from the small liberal arts college in New England:

I am a passionate advocate for those who face all injustice. I love to learn about politics, and social justice issues. I want to study law and be a judge so laws and formulation of ideas are crucial. I like to learn about why things are the way they are!

My name is Annie and I like to learn about people and culture. I find learning about people truly fascinating and consistently relevant to my professional and personal goals of becoming a social worker.

Graduate students at the mid-Atlantic university largely identified with their student status and work roles $(n=25)$. Work roles tended to be in the space of education and federal employment. Student interests tended to center around 
education, educational technology, languages, and emerging technologies, which is not surprising given their involvement in an Instructional Design Master's degree program. Similar to students at the New England College, students at the MidAtlantic university additionally identified with their country of origin, favorite hobbies, and connections to family. An important aspect to note is that many of the students at the MidAtlantic university were also working full-time and particularly interested in applying theory to practice. Below are responses that are representative of this sample population:

I am currently pursuing a M.Ed. in Instructional Design and Technology. I am also a full-time federal employee. I am interested in learning about psychology, language acquisition, new trends in learning and technology.

Professionally, I'm always interested in where the rubber meets the road - I'm very interested in how to bring in the light, so to speak, from the grounded, academic, research base into the production cycles of education and training development. I'm interested in how to apply what the science is showing us about learning.

\subsection{Q2: What hardware do you use to learn?}

With regards to the question what hardware do you use to learn, laptops dominated the responses with $96 \%$ of students reporting laptop use $(n=72)$ at the small liberal arts college $(n=75)$. Of the small liberal arts colleges' student responses, $75 \%$ reported using smartphones $(n=56)$ and $33 \%$ indicated they used tablets $(n=25)$. Only $16 \%$ of the students at the small liberal arts college reported using desktop computers $(n=12)$. On the other hand, $91 \%$ percent of students at the Mid-Atlantic university $(n=34)$ reported using smartphones $(n=31)$ and laptops $(n=31)$ for learning. Additionally, tablet usage was popular with the midAtlantic university students at $76 \%(n=26)$. Of the devices reported by the mid-Atlantic university students, $35 \%$ indicated they utilized desktops $(n=12)$. Of note is that students at the midAtlantic university were more likely to discuss the affordances (characteristics) of the different devices they used as well as when and where they would use one device over another. A response that demonstrates this observation is included below:

I like to use a desktop computer at home and at work (I enjoy looking at a big screen and working with several documents and applications open at the same time). At school and before going to bed I prefer to use a tablet (since it's very light and easy to carry around). In transport I use a phone because it's small, portable and is always connected to the Internet.

In addition to considering the affordances of the tools, midAtlantic university students described using a combination of devices to accomplish tasks with $79 \%(n=27)$ reporting using more than three devices. Using multiple devices was also observed in the responses of students at the small liberal arts college with $57 \%(n=43)$ describing the use of three or more devices for learning purposes. Figure 2 displays data about the different types of hardware students used to learn at their respective schools.

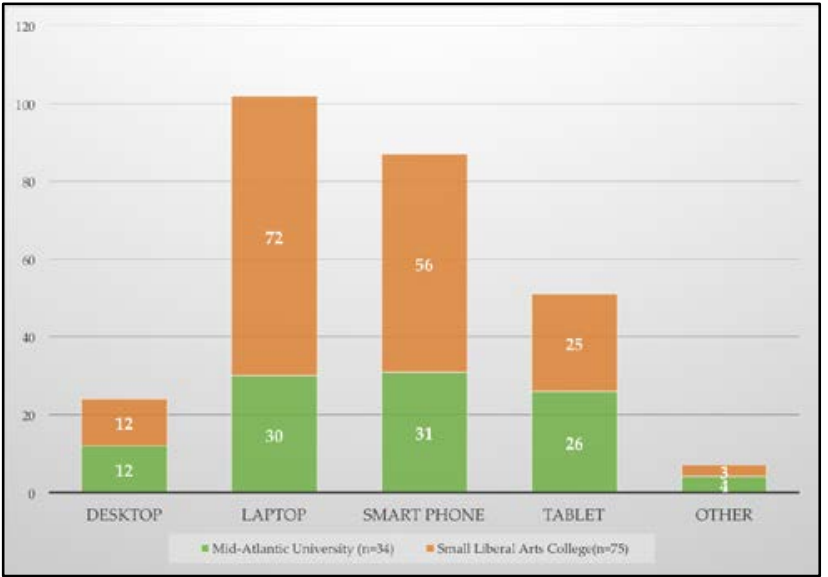

Figure 2. Frequency count of hardware use $(\mathrm{N}=109)$

\subsection{Q3: What software do you use to learn?}

Responses to this question revealed that $68 \%$ of students at the small liberal arts college tended to use search engines $(n=51)$ at the highest rates followed by $52 \%$ of students reporting the use of social networks $(n=39)$ and $45 \%$ utilizing online videos $(n=34)$. On the other hand, $85 \%$ of students at the mid-Atlantic university used videos to learn $(n=29)$ followed by $74 \%$ of students reporting use of search engines $(n=25)$ and $53 \%$ referencing eBooks $(n=18)$. In both contexts, search engines and videos were important to students in the learning process. Figure 3 displays data about the different types of software students used to learn at their respective schools.

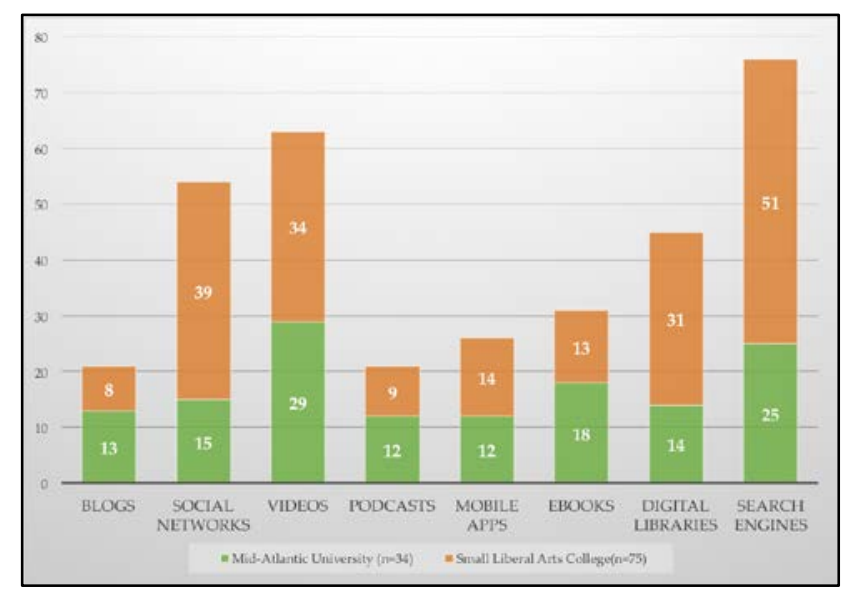

Figure 3. Frequency count of software use $(\mathrm{N}=109)$

\subsection{Q4: What digital tools do you wish you had access to for learning?}

Students at the small liberal arts college wished they had access to the following digital tools for learning: $11 \%$ indicated they wished they had access to resource management tools $(n=8)$ such as online bookmarking to help them aggregate news articles and readings to stay organized; $23 \%$ reported a desire for progress-tracking tools $(n=17)$ to facilitate instructor and student feedback, grades, and as a support tool to stay on track with expectations; and $41 \%$ of students wanted organizational tools $(n=31)$ such as graphic organizers, concept-mapping, mind- 
mapping, and infographics tools to help visually represent and organize their learning. Similarly, in a study that examined higher education students' learning strategies when using elearning as a basis for PLE development, Parra (2016) found that among the most commonly used strategy was information organization through the use of conceptual maps, summaries, databases, and references. On the other hand, $17 \%$ percent of students at the Mid-Atlantic university stated that they wished they had access to resource management tools $(n=6), 32 \%$ reported an interest in progress-tracking tools $(n=11)$, and $44 \%$ specified organizational tools $(n=15)$. It is interesting to note that students from the Mid-Atlantic university tended to be more inclined to request a wide spectrum of other tools ranging from specific content or services to collaboration tools. Organizational tools topped the list of desired tools for both groups. Figure 4 displays data about the types of digital tools students wished they had access to for learning.

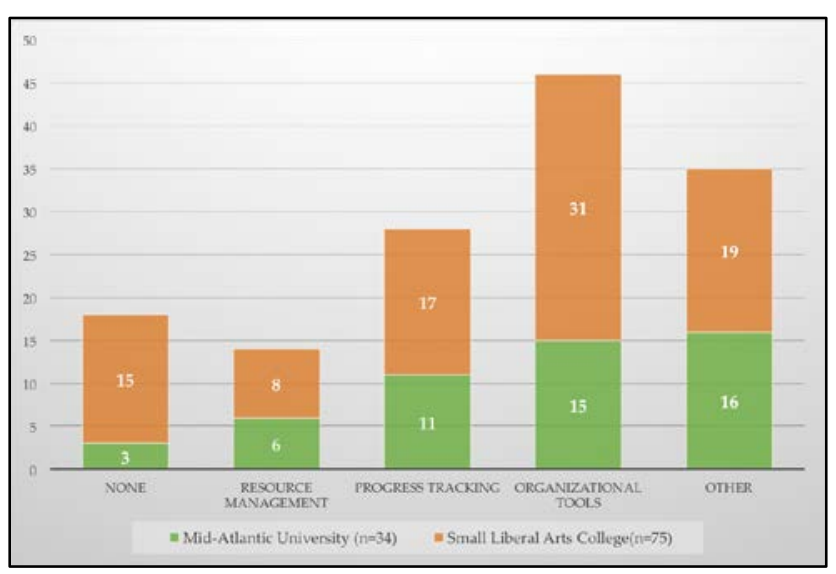

Figure 4. Frequency count, tool requests $(\mathrm{N}=109)$

\subsection{Q5: What might your ideal Personal Learning Environment (PLE) look like?}

Of the small liberal arts students surveyed, 33 (44\%) described their PLE as a physical space. Students blogged about a "quiet" $(n=13)$ "room" or "space" $(n=12)$. Physical learning spaces were characterized as having "music" ( $\mathrm{n}=7$ ) and being "comfortable" $(n=5)$ places to sit. As one student explained,

Personally, my learning environment is typically a warm place that consists of soft blankets and solitude for me to play music if I choose. I also think the [...] Center is a great resource for students and serves as a PLE for me as well. The floor is soft and it is a quiet space with rooms that are set aside so that I can play my music.

While almost half of students at the small liberal arts college saw their PLE as a physical space, others described their ideal PLE as both a physical and digital learning space $(n=30)$. Participant responses involved descriptions of what technologies and technological devices they used to perform particular tasks as well as the environments they were interested in cultivating in order to foster a productive learning environment. As one student explained, "I learn best in quiet spaces where I'm by myself and have the resources I need such as my laptop.” Parra (2016) also found that students preferred a PLE isolated from noise and distraction so as to enable better concentration and enhanced learning. The remainder of student responses to Q5 varied from a complete focus on PLEs as digital environments $(n=5)$ to confusion regarding what the term PLE meant $(n=5)$.

Within their descriptions of learning spaces, students at the small liberal arts college described places that included other learners, opportunities for discussion, conversation, and dialogue, access to educational materials, and opportunities to receive feedback on their learning progress $(n=10)$. As one student expressed,

I think I would like to have a platform where I could work on a project and ask for feedback within the same environment-- "am I on the right track with my work?” Perhaps something like a chat room off to the side and the instructor could see what I am working on and respond. Providing an immediate response -- like in a chat room -- would be wonderful, but I know that isn't possible with only one instructor.

Students also reported that they learned best in a medium sized group with plenty of opportunities for discussion, interaction and collaboration with peers and professors. As one student explained, "I would learn best in a quiet environment, but I would prefer for some students to be there in case I want to have a conversation about what I'm learning." Most quotes that mentioned other learners surrounded the desire to engage in dialogue and work collaboratively with peers and professors.

Organizing, planning, and resource management was another theme that characterized students' ideal PLE at the small liberal arts college. Students reported the need to be able to multitask, manage assignments and organize resources in a PLE. As one student expressed,

I wish I had a tool where all my news articles could be all on site. Or something that read me my articles while I'm doing homework. I use Facebook for the articles that I follow, but it would be nice to not always have Facebook up there. Also a site that had all my arguments or sources for/against a certain issue. For instance, I have a whole load of information on gun control and racism but I can't always find the article that I base my reasoning on. It's hard to save all those articles and keep it organized. Or I just don't save them and fear not being able to find them as fast. It's a mess.

It is important to note that an expressed desire for organizational and resource management tools is consistent with the students' responses to Q4, regarding which tools students wish they had access to using. Additional research should investigate which tools are the most effective for supporting students in organizational and resource management tasks in their development of PLEs.

Students were not only looking for ways to organize information, but also interested in gaining tangible experiences and participating in learning activities that supported the learning process. From these statements, experiential learning emerged as a theme for the small liberal arts college students' ideal PLE. Student responses placed a strong emphasis on hands on learning, interactive learning, engaged learning, and visual learning. Students said that they learned most effectively when they had "something in front of me rather than digitally", were "physically engaged in learning a new concept", participated in "interactive learning" or had opportunities to learn "with handson experiences”. 
Access to effective technology was yet another prominent theme characterized by the small liberal arts college student responses. For example, one student's blog stated,

My PLE would have effective technology but not so much that it overwhelmed or impeded my progress. I would have space to think and breathe without being bombarded by messages.

Another student's blog stated,

I would have a place for just writing (notes, stories, poems, etc.) and an engine for limitless research. I would want the engine to grant me access to every publication and documentation ever (accurate and inaccurate, fiction and non-fiction). I would want to be able to view any possible perspective on one topic at one time.

As apparent from these quotes, it was important for students to have access to tools that are optimized to meet their specific needs without creating any additional obstacles or distractions that could impede their learning process and progress. Having effective technology was not the only expressed desire, however. Students also wanted to feel effective using the technologies. As one student responded,

It would be nice to feel comfortable with a variety of technology so I can feel comfortable using it in my future jobs and so I am introduced to technology options I hadn't known before.

While students at the small liberal arts college tended to view their ideal PLEs as a combination of physical or physical and digital spaces, the majority of students (63\%) at the Mid-Atlantic university described their ideal PLE as a digital space $(n=22)$. Since Mid-Atlantic university students tended to view their PLEs from a digital lens, they were much more focused on the importance of technologies supporting learning on the go, being accessible on a variety of devices, enabling personalization and providing integration across multiple services and platforms. The following quotes support the digital nature of PLEs:

My ideal PLE would be a creative organized space consisting of a variety of digital tools and resources. My space would also allow for collaboration and reflection through the use of digital tools.

My PLE would be a tabula rasa. It would be a platform with a white screen and then additional tools, widgets, docs, social network feeds that I could add based on my preference. I would also like to design it how I like it, with colors, fonts, location that I prefer. It would also include a way to organize the learning process, prioritize tasks and be hyperlinked to everything.

These results align with the findings of Castañeda and Solo (2010) when they asked students to draw their PLE and found that most identified their PLE with tools and tasks, and only some went a step further to establish more complex relationships between tools, contents, tasks and personal growth.

Like the student responses from the small liberal arts college, Mid-Atlantic university students indicated that an ideal PLE would include opportunities for discussion, collaboration, and interaction. Since a majority of those students viewed PLEs through a digital lens, responses tended to focus on collaboration through the use of digital features such as chat boxes, discussion boards, and tweets. As one student explained, "I would also like to link my sources with those of peers that have similar interests as an effort to increase the level of dialogue about the topic and further my own understanding." Connecting to others through the use of social technologies was an important aspect of learning for the mid-Atlantic university students.

From an organizational, planning, and resource management perspective, the mid-Atlantic university students were interested in developing informational dashboards, aggregating and curating content of interest, and locating technology that is accessible to a variety of devices. As the following students described,

My ideal PLE would be a place to save and organize documents, webpages, photos, online tools etc., all together, in a way that is easy to separate into categories and share with others. This would be accessible with one click from any of my main devices (phone, laptop, desktop and tablet).

My ideal PLE would be digital and have supports available to help guide my learning and help organize the knowledge I acquire. I enjoy learning and organizing my learning through iCloud, that way I can use my laptop, smartphone, or tablet and the same information is available to me. This is also the reason I choose to use Google Drive. My Google Docs, Google Sheets, and Google Presentations can be accessed from any of these digital platforms. Also, my Pages and Keynote documents from my Mac computer can be accessed through iCloud on all three devices as well.

I am picturing a dashboard type of interface, with important things to do highlighted, links to my Google area for each course, links to databases and search engines, and embedded chats and meetings with my project teams.

As these quotes indicate, increasing the flexibility of tools to support 'on the go' learning and reducing the number of steps necessary to locate instructional content of interest may support future PLE and tool development.

Experiential learning strategies also characterized the MidAtlantic university's students' description of an ideal PLE, however, this theme was not as pronounced in this student sample population as it was in the small liberal arts college student sample. We hypothesize that the theme of experiential learning may not have been as explicitly represented in the responses of the mid-Atlantic university students since the institutional pedagogy emphasizes project and problem based learning. Many of the mid-Atlantic university's departments require that students create tangible artifacts that directly relate to authentic work contexts. Thus, we hypothesize that since experiential learning is foundational to the learning activities at the mid-Atlantic university, the concept of hands-on learning was not as explicitly represented in these student responses.

With respect to effective technology, Mid-Atlantic university students tended to focus on the need for their PLEs to have an effective user experience that was well designed, seamless and without compatibility issues. Students expressed the desire to learn anytime, anywhere, and 'on the go'. They described ideal PLEs that were "clean and easy to use", where they would "have the ability to customize the layout and navigational tools" and 
that could be designed "how I like it, with colors, fonts, and locations that I prefer". The following quotes represent students' desire for effective technology that supports the user experience,

I also need multiple devices and displays I can use at the same time. My mind is never just thinking about one thing and I need a workstation that can keep up with me. I want to be able to check multiple sites at once, prepare a document and design visuals simultaneously, and still be able to check facts quickly on my handheld devices. If my PLE can keep with both my mind and the changing world, I'll be golden.

My ideal PLE is definitely something that leans heavily on technology. I like the idea of short and sweet content, which is accessible on the go. I also want something clean and easy to use, since an unintuitive UI tends to get in the way of the learning. But no matter what, I want something that makes learning fun that I can do at my own pace!

These responses suggest that students' expectations regarding PLEs continue to evolve in light with the learner's needs to consume, organize, synthesize, manipulate, and present content. Figure 5 represents collective themes permeating students' descriptions of their ideal PLEs across all participants in this study.

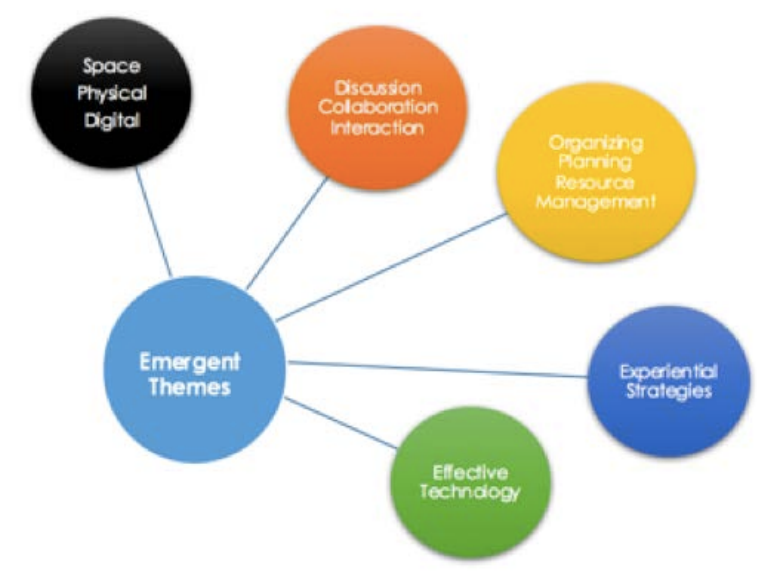

Figure 5. Emergent themes from responses to the question of what an ideal PLE might look like

\section{DISCUSSION}

This study sought to understand what digital tools college students use for learning, what digital tools college students wished they had access to for learning, and what college students' perceptions of PLEs are. PLEs can be perceived as a single student's educational or digital learning platform, allowing collaboration with other students and instructors, using technologies as tools for discovery in an effort to expand their learning experiences beyond campus boundaries, and drawing connections from a growing matrix of resources that they select and organize. The findings of this study revealed that students' perceptions of PLEs are aligned with these PLE attributes. Students reported that their ideal PLEs would include opportunities for discussion, collaboration and interaction, tools for organizing, planning, and resource management, experiential learning strategies, and the use of effective technology to support a personalized learning experience. The use of search engines, videos, and social networks, were reported as highest on the list of digital tools for learning, and organizational tools and progress tracking tools were reported as highest on the list of desired digital tools for learning. These findings suggest that PLEs are not a stable nor monolithic learning technology that can be standardized or used in a controlled environment,, rather, PLEs cross institutional and organizational boundaries and evolve over time and place (Dabbagh et al., 2015). As Haworth (2016) emphasized, PLEs are not persistent learning environments, rather, they are dynamic and evolve according to learners' objectives and achievements. Moreover, PLE tools must be dynamic to allow learners to continue to have access to learning materials across courses and institutions.

As Gillet (2013) posited, a PLE is a freely assembled ecosystem consisting of any set of communication channels, cloud resources, Web apps and social media members (Gillet, 2013). Kop and Fournier (2014) identified six components as essential in a PLE: personal profiler, aggregator, editor, scaffolds, recommender, and services (Kop \& Fournier, 2014). Some researchers (e.g., Gillet 2013; Gasevic, 2014) have developed dedicated social media systems that incorporate such components, e.g., Graasp, which stands for Grasping Resources Apps Activity Spaces and People, and ProSolo, a self-directed competency management system designed to improve the social experience of MOOC learners and increase engagement and persistence. While such systems may be effective at scaffolding a personalized learning experience, they may be understating the learner as designer principle of a PLE and formalizing the PLE process through the instantiation of yet another tool or platform. On the other hand, a PLE that relies on a variety of technological artefacts, tools, and platforms that are freely assembled by the learner could lead to interdependencies and usability issues (Dabbagh et al., 2015). Haworth (2016) proposed that different social media platforms can serve as a PLE. For example, a blog, a wiki, or a social bookmarking site can serve as a PLE. While using one social media platform as a PLE supports the open and dynamic nature of PLEs, it may be limiting in terms of collaboration with social media members or instructors who may not share similar tools.

The findings of this study also revealed that students perceived PLE development as making their learning experience more personal, connected, social, and open (Tu et al., 2012). When learning is driven by the student's internal needs, interests, motivations and preferences, as is the case in PLEs, personalization becomes intrinsic to the learner and learning becomes a personal endeavor (Ito et al., 2013; Verpoorten, 2009). Moreover, the goal of the student shifts from a recipient of information and participator in a learning experience that is designed and facilitated by the instructor, to a collector, organizer, and designer of one's own learning experience.

It has become increasingly clear that students want to own their learning and PLEs are a pedagogical and technological vehicle for supporting students' ownership of learning because PLEs are unique to their author or initiator (Dabbagh et al., 2015). However, in order for students to become successful designers, curators, and evaluators of their learning experience, they must acquire and apply knowledge management and selfregulated learning skills (Coll \& Engel, 2014; Dabbagh \& Kitsantas, 2012). Teaching students to become effective selfregulated learners may help them acquire basic and complex personal knowledge management skills that are essential for creating, managing and sustaining PLEs. As Dabbagh and 
Kitsantas (2013) suggested, engaging students in PLE development has the potential to foster self-regulated learning in conjunction with knowledge building, information management and content aggregation and collaboration. Future research should focus on the development of digital tools that support self-regulated learning, information management, and content aggregation, or an artificial intelligence agent or companion that provides a personalized learning experience as this student's blogpost description of an ideal PLE suggests:

My AI companion would be my ideal PLE. He would know my way of thinking and act both as a companion and a mentor. He would help me search the way I want to and help me stay interested in the subject. He would understand my background and present state, and guide me to a higher level of learning. He would bring me about the things I have misunderstood and broaden my limited understanding. He would bring me the vast amount of information available on the Internet yet at the same time allow me to focus on one single point of interest to me.

\section{REFERENCES}

Adell, S. J. \& Castañeda, L. (2010) The Personal Learning Environments (PLEs): a new way of understanding learning. In R. Roig Vila \& M. Fiorucci (Eds.), Keys for innovation research and educational quality. The integration of information and communications technology and Interculturalism in the classroom. Stumenti di Ricerca per l'innovaziones and the qualità in education. The dell'informazione Tecnologie e della Comunicaziones e l'nella interculturalità scuola. Alcoy/Roma: Ivory/ Universita degli Studi Tre.

Ash, K. (2013, May 20). 'Personal Learning Environments' focus on the individual. Education Week. Retrieved from

http://www.edweek.org/ew/articles/2013/05/22/32el-personallearning.h32.html

Barron, B. (2006). Interest and self-sustained learning as catalysts of development: A learning ecology perspective. Human Development, 49(4), 193-224. doi:10.1159/000094368

Castañeda, L., \& Soto, J. (2010). Building Personal Learning Environments by using and mixing ICT tools in a professional way. Digital Education Review, 18, 9-25.

Chatti, M. A. (2010). Toward a personal learning environment framework. International Journal of Virtual and Personal Learning Environments, 1(4), 66-85. doi:10.4018/jvple.2010100105

Cigognini, M. E., Pettenati, M. C., \& Edirisingha, P. (2011). Personal knowledge management skills in Web 2.0-based learning. In M. J. W. Lee \& C. McLoughlin (Eds.), Web 2.0-based e-Learning: Applying social informatics for tertiary teaching (pp. 109-127). Hershey: IGI Global. doi:10.4018/978-1-60566-2947.ch006

Clark, W., Logan, K., Luckin, R., Mee, A. \& Oliver, M. (2009). Beyond Web 2.0: Mapping the technology landscapes of young learners. Journal of Computer Assisted Learning, 25(1), 56-69. doi:10.1111/j.1365-2729.2008.00305.x

Coll, C., \& Engel, A. (2014). Introduction: Personal Learning Environments in the context of formal education / Introducción: los Entornos Personales de Aprendizaje en contextos de educación formal. Cultura y Educación, 26(4), 617-630. doi:10.1080/11356405.2014.985947

Dabbagh, N., \& Kitsantas, A. (2012). Personal Learning Environments, social media, and self-regulated learning: A natural formula for connecting formal and informal learning. The Internet and Higher Education, 15(1), 3-8. doi:10.1016/j.iheduc.2011.06.002

Dabbagh, N., \& Kitsantas, A. (2013). The role of social media in self-regulated learning. International Journal of Web Based Communities, 9(2), 256-273. doi:10.1504/IJWBC.2013.053248

Dabbagh, N., Kitsantas, A., Al-Freih, M., \& Fake, H. (2015). Using social media to develop Personal Learning Environments (PLEs) and self-regulated learning skills: A case study. International Journal of Social Media and Interactive Learning Environments,3(3), 163-183. doi:10.1504/IJSMILE.2015.072300

Dabbagh, N., \& Reo, R. (2011a). Back to the future: Tracing the roots and learning affordances of social software. In M. J. W. Lee \& C. McLoughlin (Eds.), Web 2.0-based e-Learning: Applying social informatics for tertiary teaching (pp. 120). Hershey: IGI Global. doi:10.4018/978-1-60566-294-7.ch001

Dabbagh, N., \& Reo, R. (2011b). Impact of Web 2.0 on higher education. In D. W. Surry, T. Stefurak, \& R. Gray (Eds.), Technology integration in higher educa- tion: Social and organizational aspects (pp. 174-187). Hershey: IGI Global. doi:10.4018/978-1-60960-147-8.ch013

Downes, S. (2007, February 3). What connectivism is [Blog post]. Retrieved from http://halfanhour.blogspot.com/2007/02/what-connectivism-is.html

Ebner, M. Lienhardt, C., Rohs, M., \& Meyer, I. (2010). Microblogs in higher education - a chance to facilitate informal and process-oriented learning. Computers \& Education, 55 (2010), 92-100. doi:10.1016/j.compedu.2009.12.006

EDUCAUSE Learning Initiative (ELI). (2009). The seven things you should know about... Personal Learning Environments. Retrieved from https://net.educause.edu/ir/library/pdf/ELI7049.pdf

Gasevic, D. (2014). ProSolo launched [Blog]. Retrieved from http://blog.prosolo.ca/2014/10/prosolo-launched/

Gillet, D. (2013). Personal Learning Environments as enablers for connectivist MOOCs. In Proceedings of the 12th International Conference on Information Technology Based Higher Education and Training (pp. 1-5). Antalya, Turkey. doi:10.1109/ithet.2013.6671026

Greene, J. C. (2007). Mixed methods in social inquiry. San Francisco: Jossey-Bass.

Harrison, D. (2011). Can blogging make a difference? Campus Technology. Retrieved from

http://campustechnology.com/articles/2011/01/12/can-blogging-make-adifference.aspx

Haskins, T. (2007, April 4). PLEs are power tools [Blog post]. Retrieved from http://growchangelearn.blogspot.com/2007/06/ples-are-power-tools.html

Hseih, H. F., \& Shannon, S. E. (2005). Three approaches to qualitative content analysis. Qualitative Health Research, 15(9), 1277-1288. Retrieved from http://www.iisgcp.org/pdf/glssn/Supplemental_Reading_on_Coding_2.pdf doi:10.1177/1049732305276687

Haworth, R. (2016). Personal Learning Environments: A solution for self-directed learners. TechTrends, 60, 59-364. doi:10.1007/s11528-016-0074-z

Ito, M., Gutiérrez, K., Livingstone, S., Penuel, B., Rhodes, J., Salen, K., Schor, J., Sefton-Green, J. \& Watkins, S.C. (2013) Connected learning: An agenda for research and design. Irvine, California. Retrieved from http://dmlhub.net/sites/default/files/ConnectedLearning_report.pdf

Kitsantas, A., \& Dabbagh, N. (2010). Learning to learn with Integrative Learning Technologies (ILT): A practical guide for academic success. Greenwich: Information Age Publishing.

Kop, R., \& Fournier, H. (2014). Developing a framework for research on Personal Learning Environments. Elearning in Europe Journal, 35.

Johnson, L., Adams, S., \& Haywood, K. (2011). The NMC horizon report: 2011 K12 edition. Austin, Texas: The New Media Consortium. Retrieved from http://www.nmc.org/pdf/2011- Horizon-Report-K12.pdf

Mason, R., \& Rennie, F. (2007). Using Web 2.0 for learning in the community. The Internet and Higher Education, 10(3), 196-203. doi:10.1016/j.iheduc.2007.06.003

Martindale, T., \& Dowdy, M. (2010). Personal Learning Environments. In G. Veletsianos (Ed.), Emerging technologies in distance education (pp. 177-193). Edmonton: Athabasca University Press.

Maxwell, J. (2013). Qualitative research design: An interactive approach. Thousand Oaks, California: Sage Publications.

McLoughlin, C., \& Lee, M. J. W. (2010). Personalised and self-regulated learning in the Web 2.0 era: International exemplars of innovative pedagogy using social software. Australasian Journal of Educational Technology, 26(1), 28-43. doi:10.14742/ajet.1100

Minocha, S., \& Kerawalla, L. (2011). University students' self-motivated blogging and development of study skills and research skills. In M. J. W. Lee \& C. McLoughlin (Eds.), Web 2.0-based e-Learning: Applying social informatics for tertiary teaching (pp. 149-179). Hershey: IGI Global. doi:10.4018/978-160566-294-7.ch008

Parra, B. (2016). Learning strategies and styles as a basis for building personal learning environments. International Journal of Educational Technology in Higher Education, 13(4). https://doi.org/10.1186/s41239-016-0008-z

Rubin, N. (2010). Creating a user-centric learning environment with Campus Pack personal learning spaces. PLS Webinar, Learning Objects Community. Retrieved from http://community.learningobjects.com/Users/Nancy.Rubin/Creating_a_UserCentric_Learning

Tu, C. H., Sujo-Montes, L., Yen, C. J., Chan, J. Y., \& Blocher, M. (2012). The integration of personal learning environments and open network learning environments. TechTrends, 56(3), 13-19. https://doi.org/10.1007/s11528-0120571-7

van Harmelen, M. (2008). Design trajectories: four experiments in PLE implementation. Interactive Learning Environments, 16(1), 35-46. doi:10.1080/10494820701772686

Valjataga, T., Pata, K., \& Tammets, K. (2011). Considering students’ perspective on personal and distributed learning environments. In M. J. W. Lee \& C. McLoughlin (Eds.), Web 2.0-based e-Learning: Applying social informatics for 
tertiary teaching (pp. 85-107). Hershey: IGI Global. doi:10.4018/978-1-60566294-7.ch005

Verpoorten, D. (2009). Adaptivity and autonomy development in a learning personalization process. Policy Futures in Education, 7(6), 636-644. doi:10.2304/pfie.2009.7.6.636

Wilson, S. (2008). Patterns of personal learning environments. Interactive Learning Environments, 16(1), 17-34. doi: 10.1080/10494820701772660

How to cite this article:

Dabbagh, N. \& Fake, H. (2017). College Students' Perceptions of

Personal Learning Environments Through the Lens of Digital Tools,

Processes and Spaces. Journal of New Approaches in Educational

Research, 6(1), 28-36. doi: 10.7821/naer.2017.1.215 